\title{
Transformational Leadership: From the Perspective of Neurological Leadership
}

\author{
Yaozhong Liu1, Yudan Jing1, Mei Gao² \\ ${ }^{1}$ School of Management, Jinan University, Guangzhou, China \\ ${ }^{2}$ School of Education Science, Ludong Univershity, Yantai, China \\ Email: yujianeel@163.com
}

Received 16 November 2015; accepted 13 December 2015; published 16 December 2015

Copyright (C) 2015 by authors and Scientific Research Publishing Inc.

This work is licensed under the Creative Commons Attribution International License (CC BY). http://creativecommons.org/licenses/by/4.0/

(c) $\underset{\mathrm{EY}}{\mathrm{i}}$ Open Access

\begin{abstract}
To study Transformational Leadership from the perspective of cognitive neuroscience allows us to better understand the neural basis of its behavior. After a brief introduction to Transformational Leadership and neurological leadership, this paper puts its focus on going over the neurological study which is based on resting state and functional state in the respect of individual differences in Transformational Leadership. At the same time it has also clarified the neural basis of Transformational Leadership effectiveness. Based on the neurological research on the individual differences in Transformational Leadership and behavior effectiveness, this paper also puts forward some enlightenment to improve the behavior effectiveness of Transformational Leadership. In the conclusion part, this paper has discussed certain problems in this field and its future research directions.
\end{abstract}

\section{Keywords}

Transformational Leadership, Individual Differences, Cognitive Neuroscience, Leadership Effectiveness

\section{Introduction}

The last two decades have witnessed the involvement of cognitive neuroscience in leadership research which is of great significance in better understanding leadership and guiding leadership practice. Neurological Leadership could be viewed as an applied form of cognitive neuroscience that seeks to analyze and understand behavior of leaders. It allows researchers to "examine problems within a wider analytic framework, which in turn allows for the development and testing of additional hypotheses." Previous researches on leadership phenomenon have touched deeply upon antecedent variable, consequence variable and leadership qualities. And meanwhile, some facts about individual leaders especially the incentive impacts of their personalities on their behavior have drawn the inter- 
ests of scholars into a more fundamental level, physiological level. Such things as decision-making and problem solving, collaboration and influence, emotion adjustment and transformation and so on, have effectively combined neuroscience and leadership science. In addition, leadership assessment and training based on neuroscience not only can perfect traditional leadership assessment but also can characterize itself with distinct advantages, which has already scored achievements in the respects of improving concentration, attention, and peak experience.

The most valuable kind of leadership behavior, Transformational Leadership has attracted the attention of many scholars in the field of neurology as the intermediary of social and organizational reform (Bass, 1985). This kind of leadership emphasizes how exceptionally effective leaders interact with followers in a manner that inspires them to higher levels of performance and commitment to their organizations. And in this way leaders can interact well with employees (Bass, B. M. \& Bass, R., 2009). This interaction is mainly realized through building strong beliefs, values and vision of communication. Besides, leaders will express individual consideration about employees' development needs and encourage them to think creatively in problem-solving by intellectual stimulation (Bass \& Avolio, 1994). There are four dimensions in Transformational Leadership: 1) charisma: leaders usually play a model role in strengthening employees' willingness to follow them and accept their values and principles; 2) inspirational motivation: leaders are able to convey high expectations on employees and motivate them to contribute themselves to the organization and society; 3 ) intellectual stimulation: leaders can inspire employees' intellectual so as to enhance their capability of creative thinking; 4) individual consideration: leaders create a supportive environment for employees' individual development, taking each individual's personality, needs, abilities and wishes into consideration.

Though still in its early stages, the research on Transformational Leadership from the perspective of neuroscience has obtained bountiful results. From this perspective, the current paper has first discussed Transformational Leadership and its affiliated brain mechanisms to further elaborate on some enlightenment from neuroscience theory and practice on Transformational Leadership effectiveness and its future research.

\section{Neurological Leadership Research}

\subsection{Neurological Leadership Research on Individual Differences of Transformational Leadership}

Research on individual differences of Transformational Leadership can be categorized into two types. This paper will introduce it in this chapter.

\subsubsection{Theoretical Model}

The most asked question in theoretical construction of neurological leadership is: between leadership behavior and brain activity, which one is antecedent variable and which one is consequence variable? After a systematic literature review, the writer finds that brain activity may be antecedent variable of leadership behavior while certain behavior or stimulation may also lead to some form of brain activity. Waldman et al. (2011) summarized the theoretical development of neurological leadership, sorting out two types of causality model (Figure 1) (Waldman, Balthazard, \& Peterson, 2011). The research based on model 1 explains cerebral basis of different leadership behavior through imaging brain activity in its resting state. It assumes that there are lasting and stable brain activity or structure. This kind of research is actually trait-based research of leadership; On the other hand, the research based on model 2 explains the impact of real-time leadership behavior and current stimulus on brain activity through imaging functional brain activity. It assumes that the activation of particular brain regions in brain is triggered by real-time leadership behavior or other relevant stimulus. In normal practice, this kind of research should be launched by imaging brain activity of the participant when he is given stimulation of vision, sound and touch. Then, the participant will do several different tasks. In the end, the researcher explains the functional mechanism of sense, thinking, emotion, intention and other relevant variables in leadership behavior by analyzing differences between brain structure and brain activation.

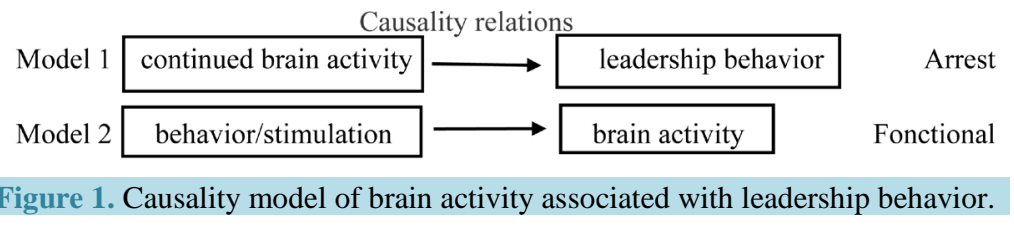


Model 1 and 2 are complementary. Studying both models can acquire the activity feature of specific brain regions and predict the functional mechanism of leadership behavior. On the other hand, new knowledge about how leadership behavior influences particular brain regions can also be detected.

\subsubsection{Relative Research Based on the Model}

To examine whether there is particularity in Transformational Leadership through Model 1 can reveal neuroscience basis in different individual traits of leadership, which can explain a set of qualities of Transformational Leadership: charisma, inspirational motivation, intellectual stimulation and individual consideration. The following studies elaborate more on this from neuroscience point of view.

Using quantitative EEG technique (qEEG), Balthazard et al. (2012) studied 200 leaders from various industries, officers from the western America Balthazard, P. A., (Waldman, Thatcher, \& Hannah, 2012). They verified the effectiveness of EEG power spectral analysis in distinguishing Transformational Leadership from nonTransformational Leadership. The study first used multivariate leadership questionnaire to assess the leaders and made a distinction between Transformational Leadership (one standard deviation above the average) and nonTransformational Leadership (one standard deviation below the average); Then, they analyzed qEEG data through neural variable reduction and selection process and on the basis of EEG power spectral analysis, they worked out and examined discriminant function, which can make valid distinction between transformational leaders according to their behavior. Therefore, based on portion variables (including brain activity indicators and brain network dynamic indicators) collected from EEG power spectrum analysis, transformational leaders can be identified and those individuals with high score can distinguish themselves from those with low scores.

The qEEG discriminant analysis in this experiment showed that compared with non-Transformational Leadership, Transformational Leadership was positively correlated with the right hemisphere of the brain asymmetry amplitude while it's negatively correlated with left hemisphere; the right side of the brain has a greater consistency while the left side has a higher distinction degree; most brain regions have a short phase-locked time and a long phase-exchange time. This indicated that there may be nerve "mark" in the distinction about Transformational Leadership.

This result was consistent with the previous neuroscience research, lying in the following facts: the right hemisphere amplitude asymmetry indicates a better mood confirmation, monitoring and management capability (Kislova \& Rusalova, 2009); a higher distinction degree in the left hemisphere of the brain reflects the brain's capability of complex thinking in analyzing problems and choosing between alternative operations; the longer phase-exchange time demonstrates that the brain is more flexible and there are additional neural resources available in solving cognitive problems.

Because studies and theories of making connection between neuroscience and leadership behavior are still in their early stages, this research, in the hope of offering a new thinking for new era leadership research, has attempted a theory construction through analyzing massive neuroscience variables and has distinguished neuroscience differences between Transformational Leadership and non-Transformational Leadership through inductive discriminant analysis.

The bases and manifestations of Transformational Leadership behavior are multidimensional. In other words, an effective leadership behavior involves emotion regulation and control, staff's emotion understanding, foresight and insight, communication skills and so on. These components are based on brain activities of different brain regions, and any transcendental theoretical connection between brain activity and corresponding leadership behavior must first analyze all the specific acts and then select evidence to support the underlying connection between neurological activity and particular behavior from existing neuroscience literature. A study on the communication of vision is also based on this idea.

Vision incentive is an behavior that belongs to Transformational Leadership behavior and has a positive impact on individuals and the whole organization (Li, 2014). In his research, Waldman et al. (2011) collected and analyzed QEEG of 50 leaders from the western region of the United States, together with assigning vision tasks, which was followed by the traditional leadership measures (employee questionnaire and self report). The results showed that the right brains of those leaders who were willing to build a social vision (emphasis on social responsibility, altruism, stakeholders authorization) bear more resemblance. Leaders who wish to build a social vision were almost the same leaders who were described by employees as incentive/charismatic leaders. But the resemblance of the right brain and staff evaluation are only marginally significant. Case analysis also corroborated this conclusion. High consistency in right brain indicates better emotional balance, understanding, reason- 
ing and overall awareness in decision-making (Thatcher, Krause, \& Hrybyk, 1986; Thatcher, North, \& Biver, 2008), which means the consistency of the right brain are more able to direct "mark" social vision construction behavior, while indirect measurements including staff evaluation lacks such a powerful prediction. This also explains how cognitive neuroscience methods make up for the shortcomings of traditional methods with their own unique advantages.

High emotional intelligence is an important feature of Transformational Leadership (Føllesdal \& Hagtvet, 2013). Researches in this area mainly focus on emotional expression, empathy, emotion management and regulation (Connelly \& Gooty, 2015). Transformational leaders have always maintained excited, enthusiastic and energetic. With their own optimism and motivation, they inspire the same feelings of employees through positive facial expressions, body language, clear expression of positive emotions. Are these leadership behavior inherent in human? A study on leadership psychological capital answered this question. Through QEEG technology, Peterson et al. (2008) found that compared with leaders with low psychological capital, leaders with high psychological capital are more active in their left prefrontal lobe, leading to a higher degree of happiness, understanding, skill to construct and understand meaning (Peterson, Balthazard, Waldman, \& Thatcher, 2008). This brain activity also represents a person's resilience, and ultimately acquire a kind of optimism in “realism”, so that transformational leaders can motivate employees in gaining confidence and overcome the difficulties.

Emotion monitoring and regulation is important for Transformational Leadership. Although under pressure, leaders can still show positive emotions or suppress negative emotions, praise employees or convey positive emotions, and they can keep calm in unknown situations (Rajah, Song, \& Arvey, 2011). Cognitive Neuroscience holds that high-level leaders' ability to express their emotions more effectively are inherent in their brains (Lu, Peng, \& Liu, 2014). Studies have shown that individuals with different mastery degree of two emotion regulation strategies-cognitive reappraisal and expression suppression show significant differences in their prefrontal lobe and right prefrontal lobe (Ochsner, Bunge, Gross, \& Gabrieli, 2002; Gross, 2002). This provides a reference for the study of the neural mechanisms of leadership emotion abilities.

The research based on model 2 aims at connecting particular leadership behaviors with specific brain regions it has activated to study the neuroscience basis of leadership behavior. Such research mainly proceeds by using functional magnetic resonance imaging (fMRI) technology. Empathy plays a very important role in "Individual Care”, namely, to accurately understand employees’ needs and emotions and give a proper feedback so as to meet their needs and training them. Researches on empathy indicate that empathy has activated the emotional system (anterior insular lobe, anterior cingulate cortex and amygdala and other marginal brain systems), mirror image nerve system and psychological theoretical systems (medial prefrontal, superior temporal sulcus, temporo-parietal junction, temporal pole etc) (Boyatzis, 2014; Yue \& Huang, 2014). Kumar believed that charisma and individual care were significantly associated with the capacity of monitoring and controlling emotions of themselves’ and others' (Kumar, 2014).

Researches on relations between Transformational Leadership and Five Human Dignity revealed effectiveness of Transformational Leadership from the perspective of personality. It has been proved that extraversion, agreeableness, responsibility have all made positive prediction for Transformational Leadership behaviors and its effectiveness (Bono \& Judge, 2004; Cavazotte, Moreno, \& Hickmann, 2012; Judge, Timothy, Bono, \& Joyce, 2000), in which extraversion manifests the most significant and the most consistent prediction (Bono \& Judge, 2004; Do \& Minbashian, 2014). Using fMRI technology, DeYoung et al., (2010) found in extraversion and blood flow in the orbital frontal cortex, which is responsible for processing reward information; agreeableness keeps blood flow covariation with brain regions which deals with processing intentions of others and psychological state (Deyoung et al., 2010). Responsibility is associated with lateral prefrontal cortex, which is responsible for planning and controlling spontaneous behavior. In addition, some scholars have studied the relations between Transformational Leadership and wisdom, gender, finding out that "recognition and uncertainty management” of wisdom are positively correlated with Transformational Leadership, and gender differences in Transformational Leadership is not eminent (Greaves, Zacher, Mckenna, \& Rooney, 1980; Martin, 2015), which provides a new direction for the future study of Transformational Leadership in the field of neurology.

Studying Transformational Leadership from the perspective of cognitive neuroscience, we can make causal explanations for leaders' differences in cognition, emotion and behavior and can link leadership phenomenon to specific brain region activities. This kind of descriptive knowledge can enhance understanding in Transformational Leadership and its theory. 


\subsection{Neurological Leadership Research on Effectiveness of Transformational Leadership}

Researches on effectiveness of Transformational Leadership generally proceed on performance dimension and attitudes dimension where attitudes dimension contains job satisfaction, organization commitment and so on. The effectiveness on a team level focuses on team innovation, team climate and organizational citizenship behavior (Meng, 2008; Chen, 2009). But researches on Transformational Leadership effectiveness and its mechanisms from the perspective of neurology are very rare. From scholars' articles published at home and abroad, we can see that the researches of Transformational Leadership effectiveness from the perspective of neurology mainly start from employees, studying information and change on the level of their cognitive nerve. However, because leadership behavior itself is a complex process that includes not only the behavior of the leaders, but also the behavior of employees and factors that trigger these behaviors, it's quite necessary to study both employees' and leaders' mind map so as to understand effective leadership more profoundly. Accordingly, the leadership was regarded as a process of share or distribution between leaders and employees rather than a specific and exclusive individual behavior. Therefore, considering effective leadership can catch inspirations from mind maps of management team and other individuals who may be not real leader.

The impact of the leaders on their employees is a matter concerns to many scholars. In Transformational Leadership study, leaders' positive emotions can convey to their employees through "emotional contagion” (including imitation and input feedback (i.e. physiological feedback in face, voice and motion)) (Palmer, Walls, Burgess, \& Stough, 2001; Luo, 2013). Studies on “emotional contagion” or "emotional infection” found that mirror neurons play an important role in this process. The emotions of the "emotion evoker" manifest through facial expressions which can be unconsciously imitated by observers and then form a feedback (forming the same emotion).

Researches on neural level showed us the important role of mirror neurons in this process. Mirror neurons can explain human imitation, language, understanding of intention and empathy and so on. In the process of emotional contagion, the mirror neural system initiates imitation and observer's imitation and feedback, in turn, will activate his mirror emotional neural system (these two systems are of the same activated neural region). Because imitation and feedback are important parts of emotional contagion mechanism, the importance of mirror neural system in the emotional contagion process is obvious (Zhang \& Lu, 2013). Through facial expressions, body languages, transformational leaders usually convey positive emotions and beautiful vision to their employees who will be unconsciously influenced. Behind all this is mirror neurons. And meanwhile, such emotional contagion is a two-way process which means employees’ feedback can also influence their leaders. Such process can keep a positive mood atmosphere in a team.

Therefore, through the angle of “emotional contagion”, it's also easy to see the important role Transformational Leadership has played in promoting team atmosphere. Moreover, the non-verbal communication, invisible collaboration between team members and leaders as well as simulation of others' intention or mental state are inseparable from the involvement of mirror neural system. When team members are interacting with each other, mirror neurons coordinate their behavior, facial expressions and body languages with others to make sure they can get along well. The transformational leaders in an organization set an example by establishing organizational climate (Becker \& Cropanzano, 2010). This “emotional contagion” process not only allows employees and leaders to maintain a positive mood in order to realize great vision and dreams, but also helps to deal with pressure scenario by effectively managing the team in organizational transformation (Rajah et al., 2011).

To convey positive emotion to employees is an important aspect of Transformational Leadership effectiveness, and positive emotions can contribute to employees' job commitment and innovation behavior etc. (Yue \& Wang, 2012; Li, Shi, Wang, \& Shi, 2013). Researches on neural level provide the basis for the fact that Transformational Leadership can promote employees' innovative spirits. Studies found positive emotions can promote creative problem-solving, execution control, cognitive flexibility, attention, decision-making and other cognitive processes by activating the frontal lobe, anterior cingulate and orbitofrontal cortex (Zhang, Cui, \& Wang, 2011). This also explains the important role that Transformational Leadership plays in promoting innovation performance of the team (Bai, 2013).

A research on the harmonious leadership has also given a hint on Transformational Leadership in influencing employees. The concept of harmonious leadership was originally put forward by Boyatzis \& McKee (2005). They believed that leadership theory must focus on how leaders remain their leadership, influence and outstanding work as well as increase their sense of happiness by maintaining "harmony within themselves" "harmony 
with others" and "harmony with the environment” (Boyatzis \& McKee, 2005; Li, 2013). Boyatzis et al. (2012) studied employees' neural substrate activity when they were recalling and they defined harmonious leadership as "interpersonal and physical coordination between the leaders and employees" and the inharmonious leadership is vice versa (Boyatzis et al., 2012).

Some simple emotions such as eye and body contact, facial expressions and tones as well as some more complicated human interactions, especially in stimulating hopeful emotion, empathy, game quality and positive emotion give birth to harmony while tense emotional signals like lack of eye contact or negative facial expressions (frown) as well as grudge, micro-management, betrayal, dullness and violation can give rise to disharmony. The study also pointed out that harmony and disharmony in leadership are associated with emotional communication, i.e. "emotional contagion." This study aimed at "harmony with others," and its description was consistent with Transformational Leadership. Therefore, we believe that Transformational Leadership is also consistent with the "harmony" mentioned in the current paper. With the help of fMRI technology, we find that when employees are recalling events concerning harmonious leadership, their brains' bilateral insular, right inferior parietal lobe and left superior temporal gyrus are obviously activated and these regions are associated with mirror neural system, social communication network or positive emotion that can stimulate one's ability to coordinate with others and to accept new ideas. But recalling inharmonious leadership has suppressed the activity of the right anterior cingulate, which will significantly activate the bilateral inferior frontal gyrus and right inferior frontal gyrus. And these regions are related to mirror neural system, evasion, narrow attention and negative emotion. One of the responsibilities of leaders is to encourage staff and keep their attention in harmony not the other way round.

Although neurological researches studying Transformational Leadership effectiveness from the perspective of employees are rare, they are of great significance. They have offered a cognitive neuroscience explanation for the effectiveness of Transformational Leadership and encouraged more researchers to explore the issue of leadership from this point of view.

\section{The Application of Neurological Leadership on Transformational Leadership Practices}

From the foregoing content, we know that starting from neuroscience, we can gain new knowledge on improving leadership behavior by using advanced neuroscience research tools (such as fMRI and PET etc.).

Human brain have a high degree of adaptability as well as stability, therefore through EEG neural feedback or nerve treatment, people can watch videos of brain and central nervous system activity by placing electrodes on the scalp. After comparing with the baseline, we can see that when brain functions well, a positive feedback will be displayed on the screen(such as a clear picture or sound) but when the brain doesn't function well, there will be a negative feedback (such as a fuzzy picture or cacophony). The purpose of neural feedback is to guide the brain to function in a positive way, that is, to enable the brain to "acquire" the desirable activity patterns and makes it the inner loop of the brain and to maintain it permanently. The combination of neural feedback and leadership training is a new attempt, but this attempt has already been applied to increasing the focus and attention control, reduce impulsive and compulsive behaviors, enhance emotional stability, and guarantee the best performance (Peterson, 2008). Applying neural feedback technology to the development and training of Transformational Leadership can achieve the desired effect by increasing the amplitude of the target band or by other ways.

Leaders' unconscious emotion can stimulate the same emotion in people they are interacting with, which is also known as emotional contagion and this process is unconsciously finished. So if a leader is in anger but he pretends to be elated. This is likely to affect the people around, causing their bad mood, and negative emotions can easily overwhelm positive ones, which requires leaders to have a high level of emotional awareness capability. This helps to establish a good relationship with the employees and pass the positive emotions to them. Dual-process theory (analytic process and social emotional thinking process)holds that when people focus on analytic tasks such as financial analysis, planning information systems or problem-solving, they activate their related network (task positive network (TPN)); when they focus on other people, like other people's emotions etc., their default network will be activated. Applying this theory to the study of leadership behavior, we can conclude that if leaders pay too much attention to the analytic process, they will inhibit the employees from accepting new things, and vice versa. 
Another relevant research shows that in the process of guidance and counseling, the empathy for personal hopes and dreams can enhance behavioral effect while the emphasis on external standard and personal vulnerability cannot guarantee the continuous change in behavior. The former (empathy) activates brain activities that are associated with vision, parasympathetic activity and positive effects while the latter (emphasis) activates brain activities that are associated with sympathetic activity, self-trait attribution and negative results (Jack et al., 2013). Therefore, a leader should not start his Monday meeting with the open remark "This is our current financial situation". He should describe a future vision that everyone desires and focus on how to lead employees to become a part of high-performance team and how to reach a higher performance than expected (rather than shareholder returns) to ensure the realization of that vision. Neuroscience tells us that if we want to inspire others, we must arouse their Positive Emotional Attractor in their brain. So in the future, transformational leaders should not only keep describing and building desirable vision but also learn to control their emotion all the time to remain optimistic and strive to lead people to that vision with positive emotions.

While leaders play an irreplaceable role in organizational change, the hindrance from employees can form an inevitable problem. Neuroscience tells us that change is painful (Rock \& Schwartz, 2007). Basal ganglia area is formed and maintained on the basis of habits, requiring less energy whereas change requires efforts (in the form of attention), and makes people uncomfortable, so people resist change. Another reason is that when people find certain unusual things, their orbitofrontal cortex will release a strong nerve signal, reducing their capability of advanced thinking. Neuroscience researches tell us spiritual experiences can make the brain maintain a state related to that experience and open relevant lines, which will not only establish chemical links in the brain but also make brain structures perform a stable physical change (Xie, 2008). In addition, our insights can create new connections that may enhance our psychological resources to overcome the resistance in the brain. Therefore, transformational leaders should lead employees' attention more frequently and effectively to the desired results of the change by identifying, encouraging, and deepening their insights and a new loop will shape in the brain as the time passes by. For example, by asking employees question, leaders can hold employees' focus on the new behavior or thoughts to inspire their insights. In short, leaders should enable the team members to focus on their own insights by facilitating discussion and business activities, after which, leaders should constantly remind the team. In this way, an enterprise map of information, mood and energy flow will become the dominant path in an organization (Rock \& Schwartz, 2007).

\section{Future Prospects}

Neurological researches on Transformational Leadership should draw useful inspirations from other disciplines and research perspectives. For example, studies have shown that Transformational Leadership may have the same genetic matrix with responsibility, extraversion and openness. Studies on responsibility have shown that the serotonin system plays an important role self-control, therefore we can carry out Transformational Leadership research on this neurological system (Spain \& Harms, 2014). Besides, there are researches exploring how genes affect the absorption of serotonin in the amygdala, and this absorption has a key role in amygdala function (Hariri \& Weinberger, 2003). What's more, interdisciplinary researches correlating with evolutionary psychology, personality psychology and other disciplines can provide new ideas and insights in our understanding of the phenomenon of Transformational Leadership.

Leadership process is complex, which involves not only the leadership qualities etc., but also aspects of employees and the background of leadership process. Achievements of neurological researches on Transformational Leadership lie more on the level of individual leaders than on employees. Therefore, future researchers their can enhance efforts in combining neural mechanism to the levels of employee and team such as employees' neural mechanisms when they are facing reform and the nerve process in emotional contagion in an organization. Researches on these issues could provide reference for improving the effectiveness of Transformational Leadership.

As for the research processes and methods, the neurological research on Transformational Leadership should focus more on the method of multi-voxel pattern analysis (Lee, Broderick, \& Chamberlain, 2007). Compared to the method of determining specific active area, multi-voxel pattern analysis can offer an analysis strategy to find the activity mode of the brain. Pure speculation on complex leadership behavior from a specific brain region or simple connection between a specific act and a particular brain region can lead neurological leadership to an extreme of "oversimplification" (reduction). Therefore, we should use of multi-layered approach to solve this 
problem, especially by combining forward reasoning and backward reasoning to determine cortical activities, and its background (Admin, 2012). In addition, complex leadership behavior may require division and cooperation of multiple parts of the brain. Therefore, future researches on neural mechanisms of leadership should expand from simply positioning brain regions to exploring corresponding brain processing networks and their operational mechanisms.

The neurological research on Transformational Leadership is still in exploring stage, and there are some common problem existing in neurological leadership itself such as theory building, ethical issues, lack of real leaders as the studying object and lack of localization research and so on. Nevertheless, we can still see that Transformational Leadership is slowly approaching and integrating with neuroscience, and relevant research papers and academic works also increase rapidly. We believe that the future neuroscience can provide new insights on Transformational Leadership research and promote innovation in its theory and practice.

\section{Conclusion}

This article describes the perspective of neuroscience and applied research in transformational leadership. It reviewed the progress of neurological transformational leadership for past two decades from two perspectives: the resting state and functional state, and brought enlightenment to the application of it in Transformational Leadership practice. Besides, it proposed some future research directions. Based on previous studies, this article hopes to propose new directions and recommendations for future studies of transformational leadership in perspective of neoroscience.

\section{References}

Admin, P. A. (2012). The Domain of Organizational Cognitive Neuroscience: Theoretical and Empirical Challenges. Journal of Management, 38, 921-931. http://dx.doi.org/10.1177/0149206312439471

Bai, M. Y. (2013). Transformational Leadership, Team Learning and Team Performance: Model and Mechanism. China University of Geosciences.

Balthazard, P. A., Waldman, D. A., Thatcher, R. W., \& Hannah, S. T. (2012). Differentiating Transformational and NonTransformational Leaders on the Basis of Neurological Imaging. Leadership Quarterly, 23, 244-258. http://dx.doi.org/10.1016/j.leaqua.2011.08.002

Bass, B. M. (1985). Leadership and Performance beyond Expectations (pp. 5244-5247). National College for School Leadership.

Bass, B. M., \& Avolio, B. J. (1994). Shatter the Glass Ceiling: Women May Make Better Managers. Human Resource Management, 33, 549-560. http://dx.doi.org/10.1002/hrm.3930330405

Bass, B. M., \& Bass, R. (2009). Bass Handbook of Leadership: Theory, Research, and Managerial Applications (4th ed.). New York: Free Press.

Becker, W. J., \& Cropanzano, R. (2010). Organizational Neuroscience: The Promise and Prospects of an Emerging Discipline. Journal of Organizational Behavior, 31, 1055-1059. http://dx.doi.org/10.1002/job.668

Bono, J. E., \& Judge, T. A. (2004). Personality and Transformational and Transactional Leadership: A Meta-Analysis. Journal of Applied Psychology, 89, 901-910. http://dx.doi.org/10.1037/0021-9010.89.5.901

Boyatzis, R. E., \& McKee, A. (2005). Resonant Leadership: Renewing Yourself and Connecting with Others through Mindfulness, Hope, and Compassion. Boston: Harvard Business School Press.

Boyatzis, R. E., Passarelli, A. M., Koenig, K., Lowe, M., Mathew, B., Stoller, J. K. et al. (2012). Examination of the Neural Substrates Activated in Memories of Experiences with Resonant and Dissonant Leaders. Leadership Quarterly, 23, 259272. http://dx.doi.org/10.1016/j.leaqua.2011.08.003

Boyatzis, R. E. (2014). Possible Contributions to Leadership and Management Development from Neuroscience. Academy of Management Learning \& Education, 13, 300-303. http://dx.doi.org/10.5465/amle.2014.0084

Cavazotte, F., Moreno, V., \& Hickmann, M. (2012). Effects of Leader Intelligence, Personality and Emotional Intelligence on Transformational Leadership and Managerial Performance. Leadership Quarterly, 23, 443-455. http://dx.doi.org/10.1016/j.leaqua.2011.10.003

Chen, Y. J. (2009). Transformational Leadership Effectiveness, Mechanism and Cultural Dependence-Theoretical and Empirical Research Based on Chinese Background. MA Dissertation, Shanghai: Fudan University.

Connelly, S., \& Gooty, J. (2015). Leading with Emotion: An Overview of the Special Issue on Leadership and Emotions. Leadership Quarterly, 26, 485-488. http://dx.doi.org/10.1016/j.leaqua.2015.07.002 
Deyoung, C. G., Hirsh, J. B., Shane, M. S., Papademetris, X., Rajeevan, N., \& Gray, J. R. (2010). Testing Predictions from Personality Neuroscience Brain Structure and the Big Five. Psychological Science, 21, 820-828. http://dx.doi.org/10.1177/0956797610370159

Do, M. H., \& Minbashian, A. (2014). A Meta-Analytic Examination of the Effects of the Agentic and Affiliative Aspects of Extraversion on Leadership Outcomes. Leadership Quarterly, 25, 1040-1053. http://dx.doi.org/10.1016/j.leaqua.2014.04.004

Føllesdal, H., \& Hagtvet, K. (2013). Does Emotional Intelligence as Ability Predict Transformational Leadership? A Multilevel Approach. Leadership Quarterly, 24, 747-762. http://dx.doi.org/10.1016/j.leaqua.2013.07.004

Greaves, C. E., Zacher, H., Mckenna, B., \& Rooney, D. (1980). Wisdom and Narcissism as Predictors of Transformational Leadership. Leadership \& Organization Development Journal, 35, 335-358.

http://dx.doi.org/10.1108/LODJ-07-2012-0092

Gross, J. J. (2002). Emotion Regulation: Affective, Cognitive, and Social Consequences. Psychophysiology, 39, $281-291$. http://dx.doi.org/10.1017/S0048577201393198

Hariri, A. R., \& Weinberger. D. R. (2003). Functional Neuroimaging of Genetic Variation in Serotonorgic Neurotransmission. Genes, Brain and Behavior, 2, 341-349. http://dx.doi.org/10.1046/j.1601-1848.2003.00048.x

Jack, A. I., Boyatzis, R. E., Khawaja, M. S., Passarelli, A. M., \& Leckie, R. L. (2013). Visioning in the Brain: An Fmri Study of Inspirational Coaching and Mentoring. Social Neuroscience, 8, 369-384. http://dx.doi.org/10.1080/17470919.2013.808259

Judge, T. A., \& Bono, J. E. (2000). Five-Factor Model of Personality and Transformational Leadership. Journal of Applied Psychology, 85, 751-765. http://dx.doi.org/10.1037/0021-9010.85.5.751

Kislova, O. O., \& Rusalova, M. N. (2009). EEG Coherence in Humans: Relationship with Success in Recognizing Emotions in the Voice. Neuroscience \& Behavioral Physiology, 39, 545-552. http://dx.doi.org/10.1007/s11055-009-9174-y

Kumar, S. (2014). Establishing Linkages between Emotional Intelligence and Transformational Leadership. Industrial Psychiatry Journal, 23, 1-3. http://dx.doi.org/10.4103/0972-6748.144934

Lee, N., Broderick, A. J., \& Chamberlain, L. (2007). What Is “Neuromarketing”? A Discussion and Agenda for Future Research. International Journal of Psychophysiology, 63, 199-204. http://dx.doi.org/10.1016/j.ijpsycho.2006.03.007

Li, C. P. (2013). Resonant Leadership: Dimension, Measurement and Its Mechanism. Advances in Psychological Science, 21, 2103-2109. http://dx.doi.org/10.3724/SP.J.1042.2013.02103

Li, C. (2014). Transformational Leadership and Team Effectiveness: The Cross-Level Mediating Effect of Intra-Team Cooperation. Management Review, 26.

Li, X., Shi, Y., Wang, Z., \& Shi, K. (2013). Resilience and Work Engagement: The Mediating Effects of Positive Coping and Positive Emotions. Management Review, 25.

Lu, H., Peng, J., Liu, Y., Education, S. O., \& University, G. (2014). Leadership Study and Application from the Perspective of Cognitive Neuroscience. Human Resources Development of China.

Luo, F. Y. (2013). How Emotion Affect Leadership Effectiveness: A Path Analysis Model. Leadership Science Forum, No. 10, 34-37.

Martin, J. (2015). Transformational and Transactional Leadership: An Exploration of Gender, Experience, and Institution Type. Portal Libraries \& the Academy, 15, 331-351. http://dx.doi.org/10.1353/pla.2015.0015

Meng, T. S. (2008). Study of Leadership Behavior in Scientific Research Team and Its Impact on Team Effectiveness. Doctoral Dissertation, Chengdu: University of Electronic Science and Technology.

Ochsner, K. N., Bunge, S. A., Gross, J. J., \& Gabrieli, J. D. E. (2002). Rethinking Feelings: An Fmri Study of the Cognitive Regulation of Emotion. Journal of Cognitive Neuroscience, 14, 1215-1229.

http://dx.doi.org/10.1162/089892902760807212

Palmer, B., Walls, M., Burgess, Z., \& Stough, C. (2001). Emotional Intelligence and Effective Leadership. Leadership \& Organization Development Journal, 22, 5-10. http://dx.doi.org/10.1108/01437730110380174

Peterson, S. J., Balthazard, P. A., Waldman, D. A., \& Thatcher, R. W. (2008). Neuroscientific Implications of Psychological Capital: Are the Brains of Optimistic, Hopeful, Confident, and Resilient Leaders Different? Organizational Dynamics, 37, 342-353. http://dx.doi.org/10.1016/j.orgdyn.2008.07.007

Rajah, R., Song, Z., \& Arvey, R. D. (2011). Emotionality and Leadership: Taking Stock of the Past Decade of Research. Leadership Quarterly, 22, 1107-1119. http://dx.doi.org/10.1016/j.leaqua.2011.09.006

Rock, D., \& Schwartz, J. (2007). The Neuroscience of Leadership. Reclaiming Children \& Youth, 16, 10-17.

Spain, S. M., \& Harms, P. D. (2014). A Sociogenomic Perspective on Neuroscience in Organizational Behavior. Frontiers in Human Neuroscience, 8, 84. http://dx.doi.org/10.3389/fnhum.2014.00084 
Thatcher, R. W., Krause, P. J., \& Hrybyk, M. (1986). Cortico-Cortical Associations and EEG Coherence: A Two-Compartmental Model. Electroencephalography \& Clinical Neurophysiology, 64, 123-143. http://dx.doi.org/10.1016/0013-4694(86)90107-0

Thatcher, R. W., North, D. M., \& Biver, C. J. (2008). Development of Cortical Connections as Measured by EEG Coherence and Phase Delays. Human Brain Mapping, 29, 1400-1415. http://dx.doi.org/10.1002/hbm.20474

Waldman, D. A., Balthazard, P. A., \& Peterson, S. J. (2011). Social Cognitive Neuroscience and Leadership. Leadership Quarterly, 22, 1092-1106. http://dx.doi.org/10.1016/j.leaqua.2011.09.005

Xie, Z. X. (2008). Organizational Change and Neurological Leadership. Board, 10, 102-102.

Yue, L. I., \& Wang, Z. M. (2012). The Influence of Procedural Justice and Innovative Behavior: The Mediating Role of Positive Mood. Soft Science.

Yue, T., \& Huang, X. T. (2014). The Network of Empathy. Journal of Southwest University: Humanities and Social Sciences Edition, No. 5, 87-94.

Zhang, Q. Y., \& Lu, J. M. (2013). What Is Emotional Contagion? The Concept and Mechanism of Emotional Contagion. Advances in Psychological Science, 21, 1596-1604. http://dx.doi.org/10.3724/SP.J.1042.2013.01596

Zhang, Y. J., Cui, L. X., \& Wang, Y. F. (2011). Cognitive Effects of Positive Emotions and Neural Mechanisms. Promoting Awareness and Capabilities of Applying Psychology to Serve the Society. Chinese Psychological Society 90th Anniversary Conference (14th National Psychology Conference Abstracts), 105-111. 